Check for updates

Cite this: J. Mater. Chem. C, 2020 8, 8069

Received 16th April 2020 Accepted 11th May 2020

DOI: $10.1039 / \mathrm{dOtc01879a}$

rsc.li/materials-c

\section{Tailoring liquid crystal honeycombs by head-group choice in bird-like bent-core mesogens $\dagger$}

\author{
Ya-xin Li, (iD ab Huifang Cheng, ${ }^{c}$ Xiangbing Zeng, (D) ${ }^{b}$ Yuan Tao, ${ }^{c}$ \\ Xiaohong Cheng (DD*cd and Goran Ungar (DD *ab
}

\begin{abstract}
We introduce a new class of mesogens that are bird-like in shape and form honeycomb-type supramolecular liquid crystals. They have a bent pi-conjugated aromatic core as wings, a linear or branched chain as the tail and a selection of functional headgroups. Honeycombs of non-centrosymmetric trigonal type $(p 3 m 1)$ are obtained, along with two different complex honeycomb superlattices (p31 $\mathrm{m}$ and $\mathrm{p2gg}$ ) and a randomized hexagonal mesophase $(p 6 \mathrm{~mm})$. The key determinant of the selfassembled structure is the nature of interaction of the headgroup with the glycerols at the ends of the wings. The structure depends on whether the sub-columns lying along the edges of the prismatic cells contain pure or mixed headgroups and wing-end hydrogen-bonding groups. Its assembly is further controlled by reducing the tail-chain volume, inducing out-of-plane buckling of the honeycomb. These two modes of symmetry breaking lead to structural polarity both in- and out-of-plane, opening the way to applications in devices relying on properties such as ferroelectricity and second harmonic generation.
\end{abstract}

\section{Introduction}

Just as there are direct ("oil-in-water") and inverse ("water-inoil") lyotropic liquid crystals (LC), ${ }^{1}$ so there are also "direct" and "inverse" thermotropic (solvent-free) LCs. While the columns in the most familiar thermotropic columnar LCs contain an aromatic core surrounded by flexible, typically aliphatic pendant chains, ${ }^{2}$ there is also a family of "inverse" columnar LCs where the rigid aromatic rods circumscribe polygonal prismatic cells with the pendant flexible chains on the inside. Such LC honeycombs are typically formed by aromatic rods (e.g. biphenyl, $p$-terphenyl, bistolane) with different weakly bonding endgroups, and having chains attached laterally. ${ }^{3}$ As the circumference of a vertical cell contains an integer number of horizontal

\footnotetext{
${ }^{a}$ State Key Laboratory for Mechanical Behaviour of Materials, Shaanxi International Research Center for Soft Materials,

$X i^{\prime}$ an Jiaotong University, Xi'an, P. R. China

${ }^{b}$ Department of Materials Sciences and Engineering, University of Sheffield,

Sheffield, UK.E-mail: g.ungar@sheffield.ac.uk

${ }^{c}$ School of Chemical Science and Technology, Yunnan University, Kunming, P. R. China

${ }^{d}$ School of Chemistry and Chemical Engineering, Yangtze Normal University, Fuling, P. R. China. E-mail: xhcheng@ynu.edu.cn

$\dagger$ Electronic supplementary information (ESI) available: Experimental methods, DSC thermograms, additional POM images, additional X-ray diffraction data, SHG and molecular modelling/simulation results on individual compounds, estimation of number of molecules per columnar stratum, electron densities of functional groups, non-bonded interaction energies and dipole moments of headgroups, synthesis and analytical data and NMR spectra. See DOI: 10.1039/ d0tc01879a
}

rods, the cells cross-section (the "tile") could have a triangular, square, pentagonal, hexagonal, or octagonal shape, and the honeycomb can have a combination of such tiles. ${ }^{4}$ If two sidechains are attached and they are different and incompatible, some very complex "multicolour" tiling patterns can be obtained. ${ }^{5}$ Such structures provide real-life models for studying physical phenomena in 2-D, ${ }^{6}$ including phase transitions and criticality, obeying universality classes analogous to those in e.g. magnetism, based on flipping molecules rather than spins. ${ }^{7}$ Meanwhile, the choice of regular polygonal nets thus created, including square and rectangular, offers a tool for directed self-assembly of sub-10 nm surface patterns for potential nanoscale electro-optic devices. ${ }^{7 b, 8}$

However, the aromatic cores do not have to be straight, and a few examples of honeycomb-generating bent core polyphiles have been reported. Their cores were bent at the centre, with the attached chain facing inward ${ }^{9,10}$ or outward ${ }^{11}$ at the bend, the two rigid arms subtending a $120^{\circ}$ angle. Mesogens with inward-facing chains are referred to as anchor-shaped. They were found to assemble in hexagonal honeycombs with either 3 or 6 molecules in the cell circumference, depending on whether the pendant chain was small or large. ${ }^{10}$ At the time it was actually not clear if the 3-molecule honeycombs had trigonal or hexagonal (randomized) symmetry. Here we introduce a new way of controlling complexity in LC honeycombs; we add a functional headgroup $\mathrm{R}_{\mathrm{h}}$ on the outside of the bend in anchor-shaped molecules, turning them into what can be described as bird-shaped. $\mathrm{R}_{\mathrm{h}}$ groups interact in different ways between themselves and with the terminal hydrogen-bonding 
groups, resulting in a variety of new controllable honeycomb structures and superlattices. Furthermore, additional frustration is introduced by reducing the size of the pendant chain (the "tail"), depriving the honeycomb of adequate filler volume and forcing it to "buckle", thus creating new opportunities. Most structures described are non-centrosymmetric, thus having interesting application potential.

\section{Results and discussion}

Six compounds were synthesised based on a symmetric bent 1,3-bis(phenylethynyl)benzene "bistolane" core with glycerol end-groups, a chain $\mathrm{R}_{\mathrm{c}}$ in 2-position (bay position) that is either a linear semiperfluorinated (denoted F) or a branched "swallow-tail" alkyl (denoted $\mathrm{H}$ ), and in addition with a functional headgroup $R_{h}$ in 5-position - see Table 1 . The compounds are thus named $R_{h}-R_{c}$. Thus the molecules can be said to have a bird-like appearance. For synthesis see the ESI. $\dagger$ The compounds were studied by polarized optical microscopy (POM), differential scanning calorimetry (DSC), small- and wide-angle X-ray scattering (SAXS and WAXS), grazing incidence SAXS and WAXS (GISAXS and GIWAXS) on thin films, second harmonic generation (SHG) light emission, and molecular modelling and molecular dynamics (MD) annealing. All compounds form liquid crystal phases that are listed in Table 1 together with their transition temperatures, transition enthalpies and lattice parameters. A complete table, including the transitions on heating from a solution-crystallized sample, is given in Table S1 of ESI. $\dagger$ DSC thermograms are shown in Fig. S1 (ESI $\dagger)$.

POM images of the compounds in the mesophases are shown in Fig. 1 and Fig. S2 (ESI $\dagger$ ). They are typical of columnar phases, with sizeable fraction of dark area indicating homeotropic alignment, where the optic axis, hence column axis, is normal to the glass substrate. Planar columns, parallel to the substrate, are prevalent in thicker samples. Bright fans are seen in Fig. 1c and e, where columns form concentric circles or arcs around the focal point. The same are seen as blue or pale-yellow in Fig. $1 \mathrm{~d}$ and $\mathrm{f}$ recorded with a $\lambda$-plate retarder; these confirm that the slow (high-index) axis is radial, hence perpendicular to the column axis. This negative birefringence is also seen in the "tumbling" defects, especially in Fig. 1a and b, appearing as thin bright streaks, where bundles of vertical columns perform a U-turn. The slow axis is seen to be parallel to the streaks, and since the columns are perpendicular, the slow axis is again confirmed as normal to the columns. This is consistent with the situation in most honeycomb LCs where the $\pi$-conjugated

Table 1 The phase transition temperatures of bird-shaped compounds

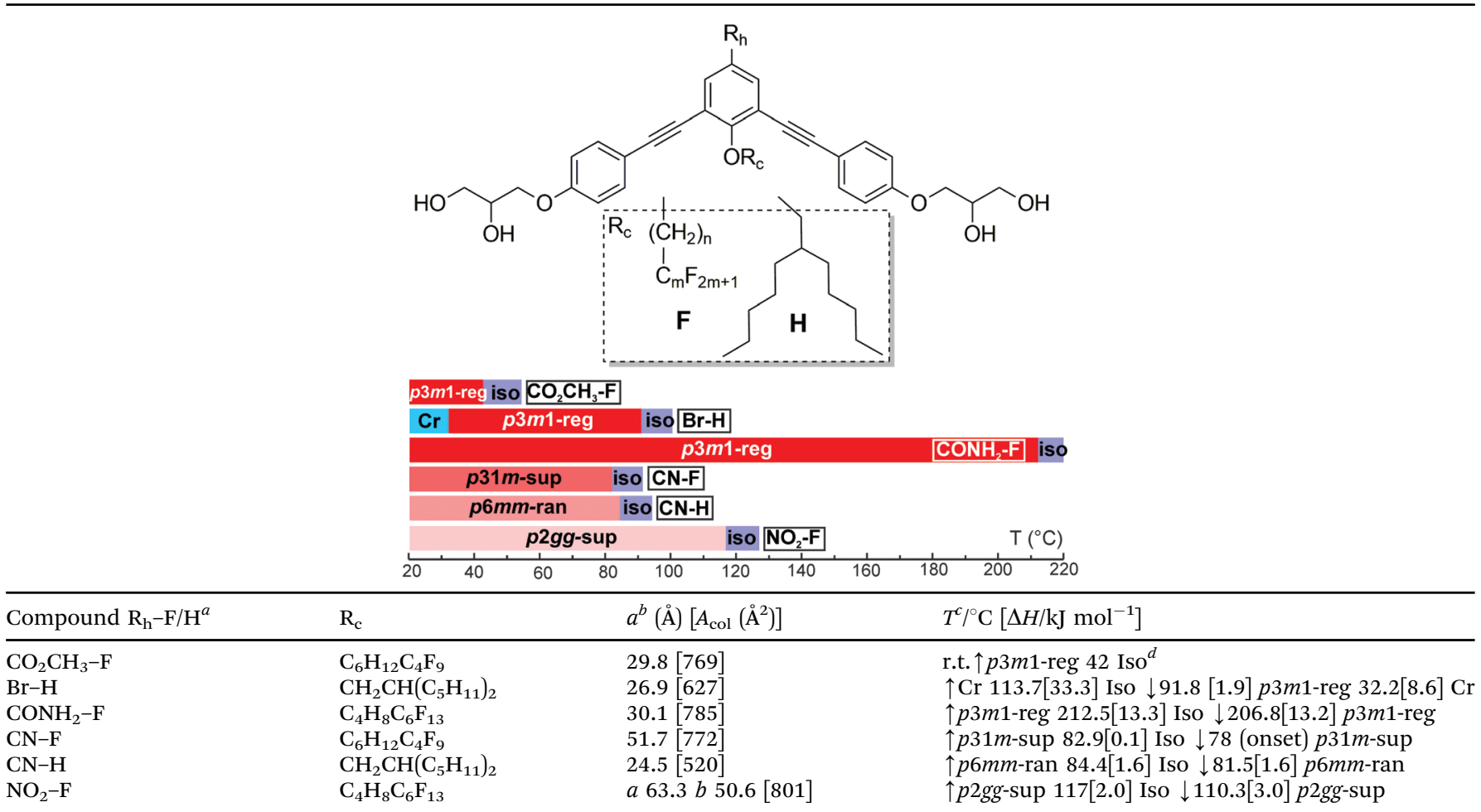

${ }^{a}$ First part of compound name is the head group $\mathrm{R}_{\mathrm{h}}$, second part denotes the type of attached chain. ${ }^{b}$ Lattice parameter [area per column in brackets]. ${ }^{c}$ Peak DSC transition temperatures [and enthalpies] on 2 nd heating $(\uparrow)$ and cooling $(\downarrow)$, all at $10 \mathrm{~K} \mathrm{~min}^{-1}$. ${ }^{d}$ Transition temperatures of $\mathrm{CO}_{2} \mathrm{CH}_{3}-\mathrm{F}$ are determined by XRD, SHG and POM. Phase abbreviations: $\mathrm{Cr}=$ crystal, $p 6 \mathrm{~mm}$-ran = hexagonal columnar phase with random orientation of the local 3-fold axis with 6-fold $p 6 \mathrm{~mm}$ overall symmetry; $p 3 \mathrm{~m} 1$-reg $=$ columnar phase with trigonal symmetry and one column per unit cell; $p 31 m$-sup = trigonal superlattice with three columns per unit cell; $p 2 g g$-sup = rectangular superlattice with $p 2 g g$ symmetry and four columns per cell; Iso = isotropic melt. Transition temperatures in the bar chart are from 2nd DSC heating, except for Br- $\mathrm{H}$ where they were determined on cooling. 
(a) $\mathrm{CONH}_{2}-\mathrm{F} p 3 m 1-\mathrm{reg}$

(b)

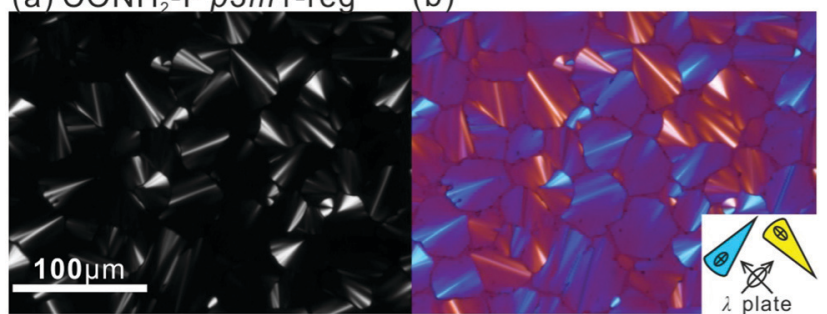

(c) CN-F p31m-sup

(d)
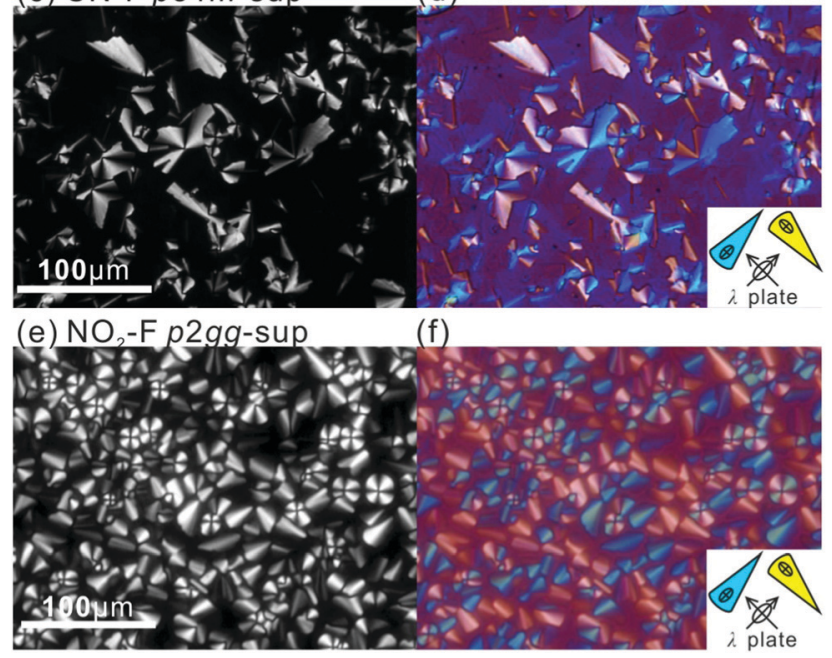

Fig. 1 Polarized optical microscopy textures of (a) and (b) $\mathrm{CONH}_{2}-\mathrm{F}$ recorded at $190{ }^{\circ} \mathrm{C}$ (cooled from $230{ }^{\circ} \mathrm{C}$ ), (c) and (d) $\mathrm{CN}-\mathrm{F}$ at $70{ }^{\circ} \mathrm{C}$ (cooled from $90{ }^{\circ} \mathrm{C}$ ) and (e) and (f) $\mathrm{NO}_{2}-\mathrm{F}$ at $100{ }^{\circ} \mathrm{C}$ (cooled from $120{ }^{\circ} \mathrm{C}$ ); $(b, d$ and $f$ ) are recorded with a full-wave $(\lambda)$ plate.

aromatic rods are perpendicular to the axis of the prismatic cells, or columns.

SAXS patterns of unoriented ("powder") samples and GISAXS patterns of thin films of the mesophases of all compounds except the nitro-compound $\mathrm{NO}_{2}-\mathrm{F}$ give Bragg peaks/ spots indexable on a $2 \mathrm{D}$ hexagonal lattice with the ratio of squared reciprocal spacings $d^{-2}{ }_{(10)}: d^{-2}{ }_{(11)}: d^{-2}{ }_{(20)}: d^{-2}{ }_{(21)}$ : $d^{-2}{ }_{(30)} \ldots=1: 3: 4: 7: 9 \ldots$ (Fig. 2a, b, 3a and Fig. S3a, S5a, ESI $\dagger$ ). GISAXS patterns of films lying on a horizontal Si substrate confirm this indexing, giving sharp spots or arcs mainly on the equator, consistent with homeotropic alignment (Fig. 2c, d and 3e). Exceptionally, compound $\mathrm{NO}_{2}-\mathrm{F}$ displays a rectangular lattice, plane group $p 2 g g$ (Fig. $3 \mathrm{~b}, \mathrm{~d}, \mathrm{~g}$ and i). Its GISAXS pattern in Fig. 3d, coming from planar domains, shows two orientations, one in which the columns lie with the (010) plane on the substrate (green reciprocal net), the other with the diagonal (210) plane on the substrate (white net). Both (010) and (210) are planes of densely packed columns, supporting the viability of the proposed structural model. The rectangular phase with its $2 b / a$ ratio of 1.60 is a distortion of a hexagonal lattice, where the equivalent ratio would be $\sqrt{ } 3$. WAXS contains only diffuse scatter centred around $2 \pi / q=4-5 \AA$, consistent with a true LC phase (Fig. S3b, ESI†). No peak around 3.5-4 $\AA$ is observed (Fig. S3b, ESI $\dagger$ ), indicating that the benzene rings do not stack as in a discotic LC with parallel discs.
The absence of a 3.5-4 $\AA$ peak suggests that the rings are inclined to the $x y$-plane and to each other.

Based on previous work on anchor-shaped molecules, ${ }^{10}$ it was reasonable to assume that the structures are based on hexagonal or, in the present case, possibly pseudo-hexagonal prismatic cells. Calculations based on unit cell area, expected average intracolumnar intermolecular distance and molecular volumes (Table S8, ESI $\dagger$ ), suggest that in $\mathrm{CO}_{2} \mathrm{CH}_{3}-\mathrm{F}, \mathrm{Br}-\mathrm{H}$, $\mathrm{CONH}_{2}-\mathrm{F}$ and $\mathrm{CN}-\mathrm{H}$ there are 3 molecules circumscribing a column rather than 6 . The fact that the unit cell areas were always close to an integer multiple $m$ of the smallest cell implies that for $m>1$ we have superlattices with $m$ prismatic columns per unit cell. Specifically, for $\mathrm{CO}_{2} \mathrm{CH}_{3}-\mathrm{F}, \mathrm{Br}-\mathrm{H}$, $\mathrm{CONH}_{2}-\mathrm{F}$ and $\mathrm{CN}-\mathrm{H} m=1$ ("regular" columnar phase). Meanwhile the unit cell of the superlattice of $\mathrm{CN}-\mathrm{F}$ contains $m=3$ columns, whereas the rectangular cell in $\mathrm{NO}_{2}-\mathrm{F}$ contains $m=4$ columns. Thus the number of molecules per unit cell $3 m$ is, respectively, 3, 9 and 12 - Table S8 (ESI $\dagger$ ).

The fact that a column stratum contains only 3 molecules raises the possibility that the structures have 3 -fold rather than 6-fold symmetry. As Laue symmetry is hexagonal in both cases, X-ray diffraction alone cannot distinguish between the two. Therefore, we tested the mesophases for the presence of SHG signal. Only $\mathrm{CN}-\mathrm{H}$ and $\mathrm{NO}_{2}-\mathrm{F}$ tested negative, while $\mathrm{CO}_{2} \mathrm{CH}_{3}-\mathrm{F}$, $\mathrm{Br}-\mathrm{H}, \mathrm{CONH}_{2}-\mathrm{F}$ and $\mathrm{CN}-\mathrm{F}$ all showed clear second harmonic emission above the background level caused by surface effects $^{12}$ (Fig. 2b and Fig. S4, S6-S8, ESI $\dagger$ ). Hence the columnar phases in these compounds are non-centrosymmetric, i.e. trigonal. In all trigonal compounds SHG intensity drops sharply to the background level near the isotropisation temperature $T_{\mathrm{i}}$.

While for hexagonal $\mathrm{CN}-\mathrm{H}$ the plane group is clearly $p 6 \mathrm{~mm}$, for trigonal phases the choice was between $p 3 m 1$ and $p 31 \mathrm{~m}^{13}$ Since neither imposes any systematic extinctions, the choice was based on the following reasoning. The columns must be centred on the 3 -fold axes, all three of which lie on the long diagonal of the rhombic unit cell in both plane groups - Fig. 4a and b. At the same time two conditions must be fulfilled. (i) To tessellate, the prismatic cells must face each other with their sides rather than edges. (ii) Since a column stratum contains three identical molecules, the mirror planes must pass through the opposing edges (apices) rather than bisecting the sides of the prisms; otherwise the prisms would acquire hexagonal rather than trigonal symmetry. For the "regular" $m=1$ phase, conditions (i) and (ii) are satisfied only if the symmetry is $p 3 m 1$, with the single column centred at $(0,0)$ (Fig. 4a). Meanwhile, for the $m=3$ superlattice of CN-F the symmetry must be $p 31 \mathrm{~m}$, with the three columns situated at $(0,0),(1 / 3,2 / 3)$ and $(2 / 3,1 / 3)$ (Fig. 4b). Accordingly, the regular 1-column trigonal phase is labelled " $p 3 m 1$-reg", and the 3 -column superlattice as " $p 31 m$-sup". In the same vein, the 4-column rectangular superlattice is labelled " $p 2 g g$-sup".

With the knowledge of mesophase symmetry, electron density (ED) maps of the xy plane were constructed from Lorentz-corrected Bragg reflection intensities (Tables S2-S7, ESI $\dagger$ ), bearing in mind that for trigonal mesophases the phase angles of certain reflections are not limited to $0^{\circ}$ or $180^{\circ}$ as in 


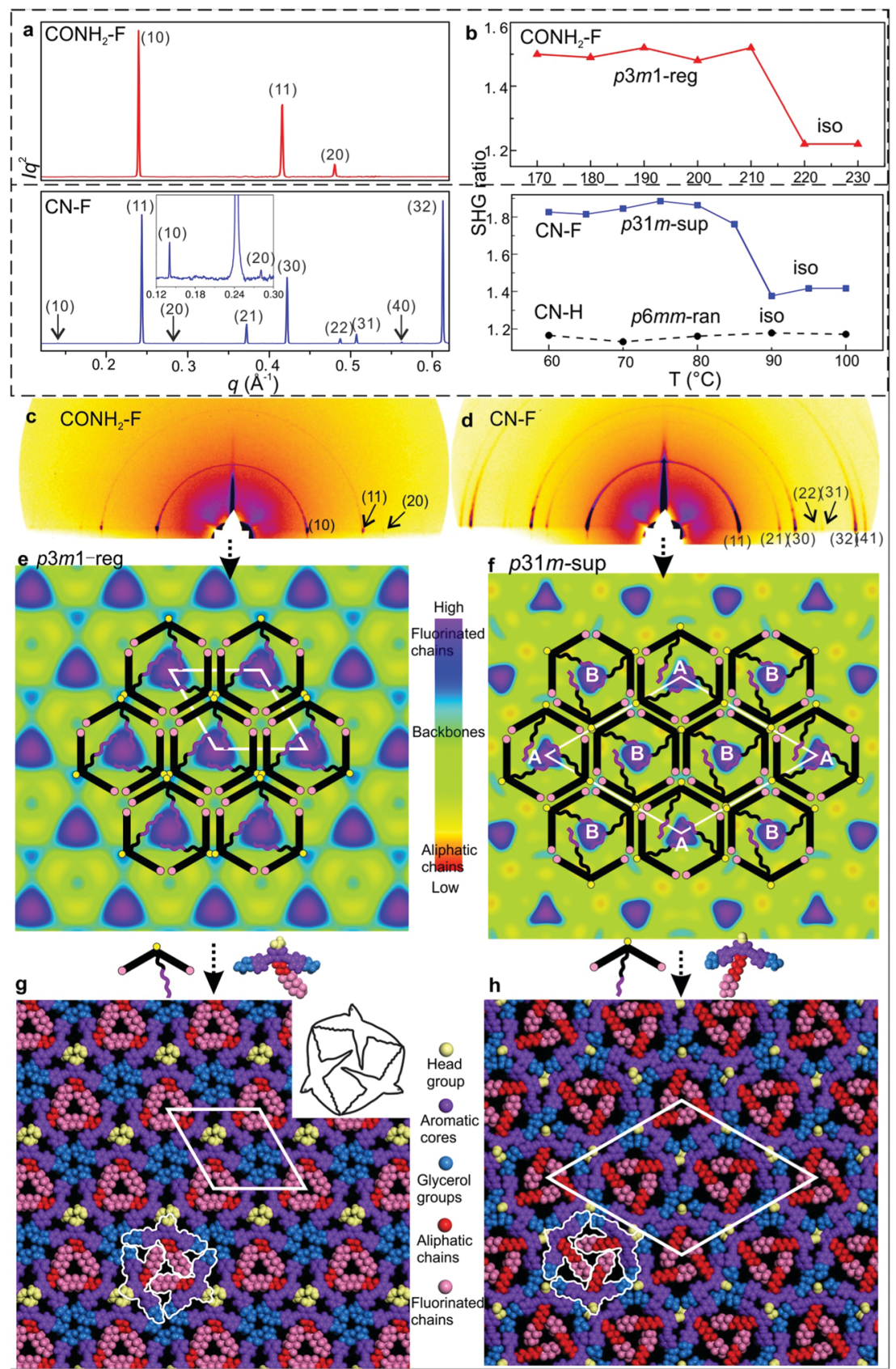

Fig. 2 (a) Powder SAXS of $\mathrm{CONH}_{2}-\mathrm{F}$ and $\mathrm{CN}-\mathrm{F}$ recorded at 130 and $70{ }^{\circ} \mathrm{C}$ upon cooling. (b) Temperature dependent intensity of the second harmonic $(400 \mathrm{~nm})$ normalized by dividing by the surrounding background level for $800 \mathrm{~nm}$ excitation, generated $20 \mu \mathrm{m}$ above the substrate surface; for measurements at different heights see Fig. S7 and S8 (ESI†). (c) and (d) GISAXS patterns of $\mathrm{CONH}_{2}-\mathrm{F}$ and $\mathrm{CN}-\mathrm{F}$ recorded at 100 and $60{ }^{\circ} \mathrm{C}$ upon cooling. (e) and (f) ED maps with schematic models of $\mathrm{CONH}_{2}-\mathrm{F}$ (p3m1-reg) and $\mathrm{CN}-\mathrm{F}$ (p31m-sup). (g) and (h) Snapshot of dynamic simulation of CONH ${ }_{2}-\mathrm{F}$ (p3m1-reg) and CN-F (p31m-sup).

the usual centrosymmetric LCs. In choosing the correct map we were guided by the above reasoning and by the $\mathrm{ED}$ values calculated for the specific parts of the molecules (Table S10, ESI $\dagger$ ). The map for $\mathrm{CONH}_{2}-\mathrm{F}$, representative of the $p 3 m 1$-reg phase, is shown in Fig. 2e, and that for the $p 31 \mathrm{~m}$-sup phase of $\mathrm{CN}-\mathrm{F}$ in Fig. 2f. The structure factor phase angles are given in Tables S4 and S5, ESI. $\dagger$ While the aromatic and glycerol groups ("backbones") have similar medium ED (green), the stand-out high-ED features are the three perfluoro chains in the centre of each column (blue-purple triangles). We associate the apices of the high-ED triangles with the positions of attached chains, close to the bay position on the aromatic cores. Schematic molecules at positions compatible with the maps are superimposed. In the $p 3 m 1$-reg phase the implication is that there are separate glycerol and amide sub-columns at alternative honeycomb nodes, each having, respectively, either 6 glycerols (6Gly) or 3 headgroups $\left(3 R_{h}\right)$ in a stratum (Fig. 2e and $4 a$ ). As the former sub-columns will be wider than the latter, the 

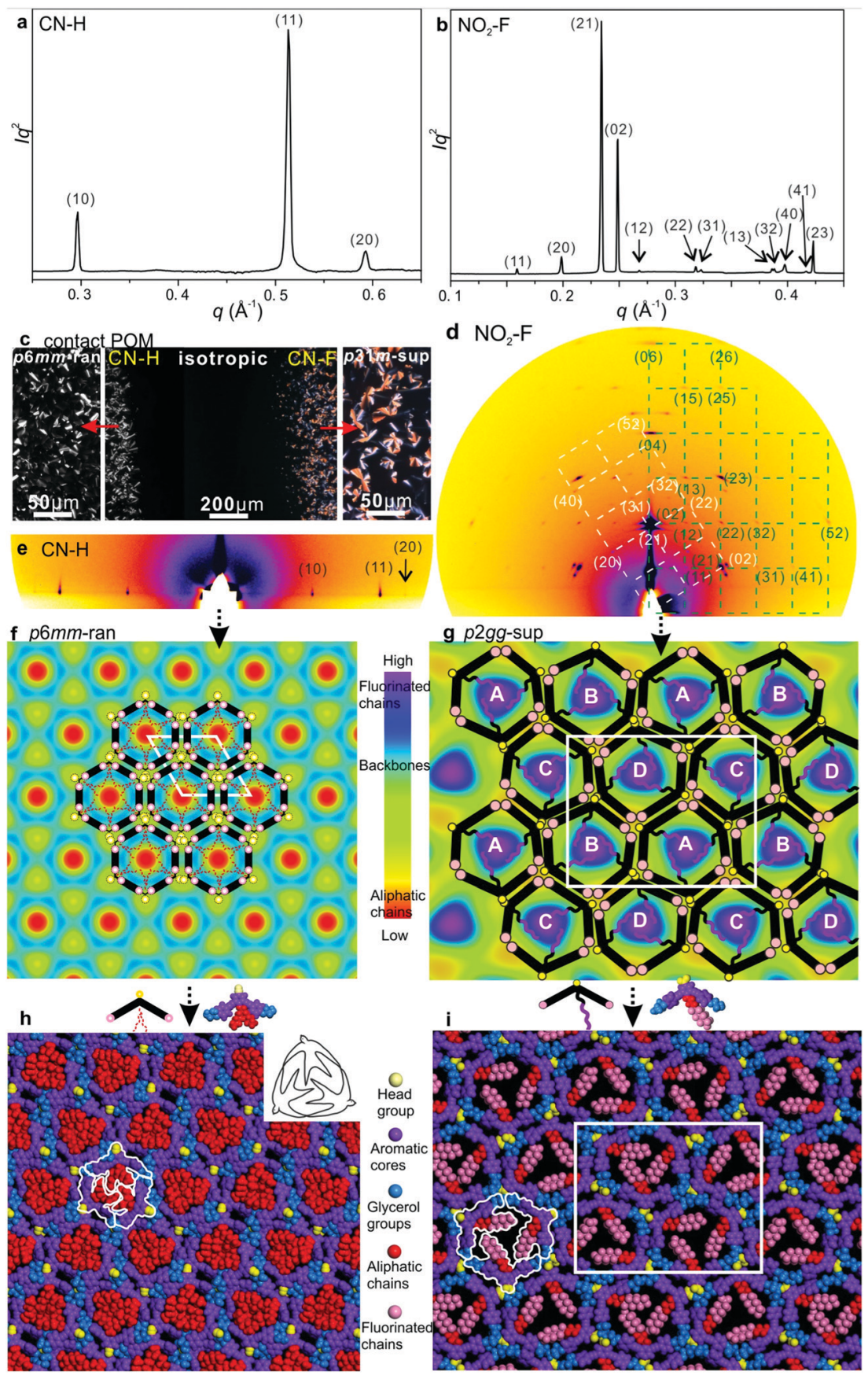

Fig. 3 (a) and (b) Powder SAXS of $\mathrm{CN}-\mathrm{H}$ and $\mathrm{NO}_{2}-\mathrm{F}$ recorded at 70 and $100{ }^{\circ} \mathrm{C}$ upon cooling. (c) POM of a contact preparation of $\mathrm{CN}-\mathrm{H}$ and $\mathrm{CN}-\mathrm{F}$ (columnar) with a mixture in the middle (isotropic), recorded at $40{ }^{\circ} \mathrm{C}$; the film is uniform in thickness; zoomed-in insets on left and right. (d) and (e) GISAXS patterns of $\mathrm{CN}-\mathrm{H}$ and $\mathrm{NO}_{2}-\mathrm{F}$ recorded at $70{ }^{\circ} \mathrm{C}$ and $100{ }^{\circ} \mathrm{C}$, respectively, upon cooling. Green and white reciprocal lattices in (d) show two different orientations of planar columns, with their (010) and (210) plane, respectively, facing the substrate. ( $f$ ) and (g) ED maps with schematic models of $\mathrm{CN}-\mathrm{H}$ (p6mm-ran) and $\mathrm{NO}_{2}-\mathrm{F}$ (p2gg-sup) mesophases. (h) and (i) Snapshot of dynamically annealed $\mathrm{CN}-\mathrm{H}$ (p6mm-ran) and $\mathrm{NO} \mathrm{m}_{2}-\mathrm{F}$ (p2gg-sup).

hexagonal prisms are likely to be distorted as shown in an exaggerated way in Fig. 4a. Meanwhile in the $p 31 \mathrm{~m}$-sup phase of CN-F (Fig. 2f and 4b), the triangles follow an up-down-down sequence along any of the three $\{110\}$ planes (labelled A, B, B in Fig. $2 \mathrm{f}$ and $4 \mathrm{~b}$ ). Hence there are again two types of sub-columns, but both are mixed, half of them containing $4 \mathrm{Gly}+1 \mathrm{CN}$ and the other half $2 \mathrm{Gly}+2 \mathrm{CN}$.
To check the viability of the proposed structures, using experimental lattice parameters molecular models were built and subjected to $N V T$ molecular dynamics annealing. As shown in Fig. 2g, h and Fig. S3d and S5d (ESI $\dagger$ ), good space-filling is achieved with no overcrowding and no voids. The tessellating bird-like molecules, outlined in black in Fig. $2 \mathrm{~g}$ and $3 \mathrm{~h}$, are reminiscent of some of the drawings of birds and bats by M. C. Escher. ${ }^{14}$ 


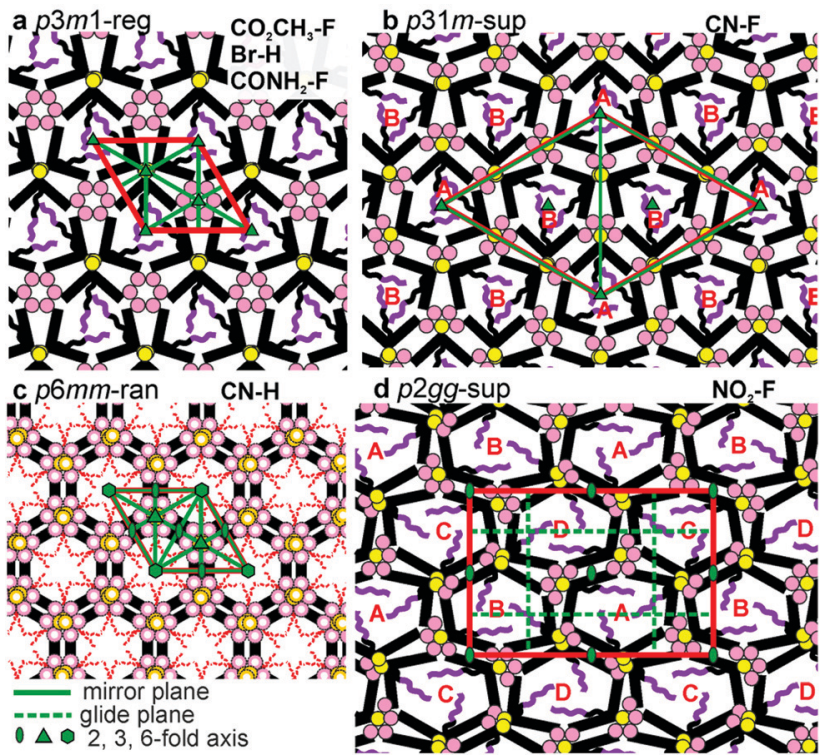

Fig. 4 Schematics of the four different honeycomb types formed by the bird-shaped molecules. Plane groups and compounds are identified, respectively, in the top left and top right corners of each panel. The bent cores are black, end-glycerols pink and headgroups yellow. The hexagon distortions are exaggerated for clarity. Unit cells are drawn in red, symmetry elements (mirror planes and rotation axes) in green, but glide planes (dashed) are only shown in (d). In (b) some mirror planes coincide with unit cell edges. (c) Shows space-time averaged structure with each empty circle dashed line chain indicating half-occupancy; thus each node contains 3 glycerols and $1.5 \mathrm{CN}$-groups on average.

As mentioned, $\mathrm{CN}-\mathrm{H}$ is the only compound with hexagonal Laue symmetry that shows no SHG signal. This means that, even if it still has only 3 molecules in the unit cell, its honeycomb phase does have an inversion centre and therefore has plane group p6mm. Here electron density has a minimum rather than a maximum in the centre of the column (Fig. 3f), as the pendant chains are low-ED aliphatic (see Table S10, ESI $\dagger$ ). Incidentally, a similar situation is seen in $\mathrm{Br}-\mathrm{H}$ (Fig. S5c, ESI $\dagger$ ). To explain the high symmetry of the $16 \mathrm{~mm}$ phase in $\mathrm{CN}-\mathrm{H}$, we propose that the honeycomb actually contains small trigonal domains which are, however, randomized in orientation; hence the long-range order, as seen by SAXS, is hexagonal. Accordingly, the mesophase is denoted "p6mm-ran". Accordingly, although there may still be some local partial separation of glycerols and cyano-groups, the average composition of all sub-columns is the same, namely $1 / 2(6 \mathrm{Gly}+3 \mathrm{CN}$ ) or $3 \mathrm{Gly}+1.5 \mathrm{CN}$ (see models in Fig. $3 \mathrm{f}$ and $4 \mathrm{c}$ ), where empty circles and dashed-lined chains indicate half occupancy. Note that the pale-blue ED maxima in Fig. 3f indicate the positions of chain attachment and branching points. A snapshot of annealed molecular model is shown in Fig. $3 \mathrm{~h}$.

The only mesophases with the ratio of $d^{-2}$ values not obeying the hexagonal rule is the rectangular $p 2 g g$-sup phase in $\mathrm{NO}_{2}-\mathrm{F}$. The plane group $p 2 g g$ is determined based on the absence of $(h 0)$ and $(0 k)$ Bragg reflections with odd $h, k$ (Fig. $3 \mathrm{~b}$ and $\mathrm{d}$ ). The schematic depiction of the $x y$ plane is shown in Fig. $4 \mathrm{~d}$. The apices of the distorted triangular high-ED fluoroalkyl regions in Fig. $3 \mathrm{~g}$ again mark the chain attachment points, hence the positions of the centres of molecules. They reveal that there are four different orientations of the distorted hexagonal columns in a unit cell, labelled A, B, C, D in Fig. $3 \mathrm{~g}$ and $4 \mathrm{~d}$. As in the trigonal superlattice of $\mathrm{CN}-\mathrm{F}$ but replacing the $\mathrm{CN}$ headgroup with $\mathrm{NO}_{2}$, there are two types of sub-columns, one containing $4 \mathrm{Gly}+1 \mathrm{NO}_{2}$ and the other $2 \mathrm{Gly}+2 \mathrm{NO}_{2}$. If we call the $4 \mathrm{Gly}+1 \mathrm{R}_{\mathrm{h}}$ sub-column "large" $(\mathrm{L})$ and the $2 \mathrm{Gly}+2 \mathrm{R}_{\mathrm{h}}$ sub-column "small" (S), then the difference between the two superlattices is in that going around a distorted hexagon the apex sequence in p31m-sup of CN-F is LSLSLS, while in $p 2 g g$-sup of $\mathrm{NO}_{2}-\mathrm{F}$ it is LLSSLS.

A further notable feature of the present mesophases is the significantly smaller cross-sectional area of columns filled with branched aliphatic chains compared to those filled with semiperfluoroalkyls - Table 1 and Fig. S9 (ESI $\dagger$ ). The average area of columns in $\mathrm{Br}-\mathrm{H}$ and $\mathrm{CN}-\mathrm{H}$ is $573 \AA^{2}$, while in fluorinated compounds it is $782 \AA^{2}$. At the same time the estimated average intracolumnar spacings $(c)$ between molecules are, respectively, $5.5 \AA$ and $4.2 \AA$ (Table S8, ESI $\dagger$ ). Since the bent core backbones are the same, we conclude that in $\mathrm{Br}-\mathrm{H}$ and $\mathrm{CN}-\mathrm{H}$ their long axis is inclined to the $x y$ plane instead of being parallel to it. This conclusion is further supported by the observed lower birefringence of $\mathrm{H}$-compounds compared to that of the F-compounds. This is apparent already by qualitative POM inspection of a contact preparation in Fig. 3c, showing a film of uniform thickness, with $\mathrm{CN}-\mathrm{H}$ on the left and $\mathrm{CN}-\mathrm{F}$ on the right. While $\mathrm{CN}-\mathrm{F}$ is coloured, $\mathrm{CN}-\mathrm{H}$ is not. Optical retardation $(\Gamma)$ of $\mathrm{CN}-\mathrm{F}$ and $\mathrm{CN}-\mathrm{H}$ is also measured quantitatively by Berek compensator, giving $\Gamma$ as -436 and $-174 \mathrm{~nm}$, respectively. As $\Gamma$ is proportional to the order parameter $S$, where

$$
S=\left(3\left\langle\cos ^{2} \theta\right\rangle-1\right) / 2
$$

we can calculate $\theta$, the angle between the molecular backbone and the columnar $(z)$ axis. Assuming perfect in-plane orientation of backbones in $\mathrm{CN}-\mathrm{F}$, i.e. $\theta_{\mathrm{CN}-\mathrm{F}}=90^{\circ}$ and $S_{\mathrm{CN}-\mathrm{F}}=-0.5$, and knowing that $\Gamma_{\mathrm{CN}-\mathrm{H}}=0.4 \Gamma_{\mathrm{CN}-\mathrm{F}}$, we get $\theta_{\mathrm{CN}-\mathrm{H}}=63^{\circ}$ for $\mathrm{CN}-\mathrm{H}$ and its complement $90^{\circ}-\theta_{\mathrm{CN}-\mathrm{H}}=\phi_{\mathrm{CN}-\mathrm{H}}=27^{\circ}$, which is the tilt angle of $\pi$-conjugated $\mathrm{CN}-\mathrm{H}$ backbones to the $x y$ plane. Alternatively, we can calculate $\theta_{\mathrm{CN}-\mathrm{H}}$ by calculating the reduction in circumference of the hexagon using the square root of the ratio of column areas $\left(A_{\mathrm{H}} / A_{\mathrm{F}}\right)^{0.5}=0.856=\arccos \phi_{\mathrm{CN}-\mathrm{H}}$, wherefrom we get $\phi_{\mathrm{CN}-\mathrm{H}}=31^{\circ}$. The fact that the two $\phi$-values are close suggests that indeed every backbone tilts by angle $\phi$, implying that the hexagon in $\mathrm{CN}-\mathrm{H}$ collapses like an umbrella.

It should be mentioned that this is not the first example of tilted backbones in honeycomb LCs. Examples were reported in a hexagonal facial amphiphile ${ }^{15}$ and a square honeycomb of a straight rod-like glycerol-terminated bolaamphiphile, ${ }^{16}$ both with a laterally attached flexible chain. In both cases $\theta$ changed steeply with temperature with $S$ passing through zero causing birefringence inversion. However, in vast majority of honeycombs $\theta=0$, presumably to maximize entropy by allowing transverse self-diffusion. If filler volume is reduced and $\theta$ remains $0^{\circ}$, in most cases the system chooses a smaller polygon. Thus hexagonal gives way to pentagonal or square. ${ }^{4 b}$ However a change from square to triangle reduces the area to 
$\sqrt{ } 3 / 4=0.43$, evidently too drastic a jump for the system in ref. 16, which chooses the tilt alternative. Other systems have opted for a combination of squares and triangles. ${ }^{5}$ However, in the present case what prevents $\mathrm{CN}-\mathrm{H}$ and $\mathrm{Br}-\mathrm{H}$ from switching from hexagons to pentagons or squares must be the fixed $120^{\circ}$ bend in the aromatic core.

Finally, we propose an explanation for the key effect of headgroup on phase structure and stability. Compared to compound $2 \mathrm{~b}$ in ref. 10 with no headgroup $\left(\mathrm{R}_{\mathrm{h}}=\mathrm{H}\right)$ and with a $\left(\mathrm{CH}_{2}\right)_{4} \mathrm{C}_{6} \mathrm{~F}_{13}$ chain, having a $T_{\mathrm{i}}$ of $190{ }^{\circ} \mathrm{C}$, all current compounds except the amide have lower $T_{\mathrm{i}}$. This reflects the packing disturbance caused by the headgroup, also notable by the, on average, 9\% larger area per column in F-compounds compared to that in the headless $2 \mathrm{~b}$ (Table S9, ESI $\dagger$ ). The disturbance is partially compensated or even overcompensated by hydrogen bonding and/or dipolar interaction of the headgroups. The lowest $T_{\mathrm{i}}$, $40{ }^{\circ} \mathrm{C}$, is found in the ester, where such interactions are at best weak, while the amide's H-bonds overcompensate lifting $T_{\mathrm{i}}$ to $212{ }^{\circ} \mathrm{C}$ (Table 1).

One would expect the headgroups and glycerols to segregate in separate sub-columns, which is what indeed happens in the p3m1-reg phase of $\mathrm{CO}_{2} \mathrm{CH}_{3}-\mathrm{F}, \mathrm{Br}-\mathrm{H}$ and $\mathrm{CONH}_{2}-\mathrm{F}$. But clustering together all the bulky glycerol endgroups carries an energy penalty of distortion of the hexagons (Fig. 4a). We propose that avoiding such distortion is responsible for mixed rather than chemically pure sub-columns in $\mathrm{CN}-\mathrm{F}$ and $\mathrm{NO}_{2}-\mathrm{F}$. In these two compounds the energies of mutual dipolar interaction between the headgroups and their H-bonding interaction with the glycerols are of the same order of magnitude. The driving force for segregation is thus weaker, so that by mixing and keeping the subcolumn volumes similar, distortion is reduced. This results in the formation of $p 31 m$ and $p 2 g g$ superlattices. Data in Table S11 (ESI $\dagger$ ) indeed suggest that $\mathrm{AB}$ cross-interactions of $\mathrm{CN}$ and $\mathrm{NO}_{2}$ groups with glycerol are similar in energy to $\mathrm{AA}$ and $\mathrm{BB}$ homo-interactions within their own species.

Returning to compounds $\mathrm{CO}_{2} \mathrm{CH}_{3}-\mathrm{F}, \mathrm{Br}-\mathrm{H}$ and $\mathrm{CONH}_{2}-\mathrm{F}$ that do not form a superlattice and where headgroups and glycerols do not mix, we may ask what these three compounds have in common. We propose that since the ester and bromo groups do not interact strongly with hydroxyl groups, mixing them with glycerol would only dilute the H-bonding within the glycerol sub-columns. The resulting energy penalty would outstrip the benefit of reduced lattice and molecular distortion. In sharp contrast, amide groups in $\mathrm{CONH}_{2}-\mathrm{F}$ H-bond more strongly among themselves than with the glycerols (Table S11, ESI $\dagger$ ). So in $\mathrm{CONH}_{2}-\mathrm{F}$ it is the amide $\mathrm{H}$-bonds that would lose out most by mixing. Again, the accompanying reduction in distortion would not be sufficient to compensate.

Regarding compound $\mathrm{CN}-\mathrm{H}$, we refrain from speculating about the situation in its $p 6 \mathrm{~mm}$-ran phase as the detailed shortrange configuration in its randomized clusters is not known.

\section{Conclusion}

This work presents a novel approach to designing complex self-assembled nano-patterns in functional materials. Most LC honeycombs so far have had identical, usually H-bonded nodes. By introducing bird-shaped mesogens based on bent $\pi$-conjugated cores with attached alkyl or fluoroalkyl tails and an additional functional headgroup of different kinds one can create new 2D lattices and superlattices. The work shows that the nanopatterns thus created can have potentially exploitable ferroelectric, pyroelectric or piezoelectric properties associated with non-centrosymmetric structures. The above results also show how out-of-plane tilt can be enforced upon the honeycombs by reducing side-chain "filler" volume, offering another route to symmetry-breaking normal to the honeycomb plane with interesting consequences for applications. These are currently investigated further.

\section{Conflicts of interest}

The authors declare no competing financial interest.

\section{Acknowledgements}

For support with experiments at synchrotron radiation sources we are grateful to Dr Olga Shebanova and Prof. Nick Terill at station I22, Dr Gareth Nisbet and Prof. Steve Collins at station I16, Diamond Light Source, and Drs Oier Bikondoa and Paul Thompson at EPSRC-funded XMaS beam line (BM28) at ESRF. Financial support is acknowledged from the 111 Project 2.0 of China (BP2018008), from EPSRC (EP-P002250, EP-T003294), from NSFC (grants 21674099, 21664015, 21865038) and Yunnan Joint Fund Key Project (2018FY001(-012)). YXL thanks CSC for stipend and UoS for fee waiver.

\section{References}

1 J. M. Seddon and R. H. Templer, Polymorphism of LipidWater Systems, in Handbook of Biological Physics, ed. R. Lipowsky and E. Sackmann, Elsevier, Amsterdam, 1995, ch. 3, vol. 1, pp. 97-160.

2 (a) C. Destrade, P. Foucher, H. Gasparoux, N. H. Tinh, A. M. Levelut and J. Malthete, Mol. Cryst. Liq. Cryst., 1984, 106, 121-146; (b) F. Vera, J. L. Serrano and T. Sierra, Chem. Soc. Rev. , 2009, 38, 781-796; (c) M. A. Shcherbina, X. B. Zeng, T. Tadjiev, G. Ungar, S. H. Eichhorn, K. E. S. Phillips and T. J. Katz, Angew. Chem., Int. Ed., 2009, 48, 7837-7840; (d) T. Ghosh and M. Lehmann, J. Mater. Chem. C, 2017, 5, 12308-12337; (e) T. Kato, N. Mizoshita and K. Kishimoto, Angew. Chem., Int. Ed., 2006, 45, 38-68; $(f)$ B. Donnio, S. Buathong, I. Bury and D. Guillon, Chem. Soc. Rev., 2007, 36, 1495-1513; $(g)$ T. Wohrle, I. Wurzbach, J. Kirres, A. Kostidou, N. Kapernaum, J. Litterscheidt, J. C. Haenle, P. Staffeld, A. Baro, F. Giesselmann and S. Laschat, Chem. Rev., 2016, 116, 1139-1241; (h) Y. X. Li, F. F. Fan, J. Wang, L. Cseh, M. Xue, X. B. Zeng and G. Ungar, Chem. - Eur. J., 2019, 25, 13739-13747.

3 (a) C. Tschierske, Angew. Chem., Int. Ed., 2013, 52, 8828-8878; (b) G. Ungar, C. Tschierske, V. Abetz, R. Holyst, M. A. Bates, 
F. Liu, M. Prehm, R. Kieffer, X. Zeng, M. Walker, B. Glettner and A. Zywocinski, Adv. Funct. Mater., 2011, 21, 1296-1323; (c) C. Tschierske, C. Nurnberger, H. Ebert, B. Glettner, M. Prehm, F. Liu, X. B. Zeng and G. Ungar, Interface Focus, 2012, 2, 669-680.

4 (a) X. H. Cheng, M. Prehm, M. K. Das, J. Kain, U. Baumeister, S. Diele, D. Leine, A. Blume and C. Tschierske, J. Am. Chem. Soc., 2003, 125, 10977-10996; (b) B. Chen, X. B. Zeng, U. Baumeister, G. Ungar and C. Tschierske, Science, 2005, 307, 96-99; (c) S. Poppe, A. Lehmann, A. Scholte, M. Prehm, X. Zeng, G. Ungar and C. Tschierske, Nat. Commun., 2015, 6, 8637; (d) A. Scholte, S. Hauche, M. Wagner, M. Prehm, S. Poppe, C. L. Chen, F. Liu, X. B. Zeng, G. Ungar and C. Tschierske, Chem. Commun., 2020, 56, 62-65.

5 (a) X. Zeng, R. Kieffer, B. Glettner, C. Nürnberger, F. Liu, K. Pelz, M. Prehm, U. Baumeister, H. Hahn and H. Lang, Science, 2011, 331, 1302-1306; (b) F. Liu, R. Kieffer, X. Zeng, K. Pelz, M. Prehm, G. Ungar and C. Tschierske, Nat. Commun., 2012, 3, 1104.

6 (a) A. J. Crane, F. J. Martinez-Veracoechea, F. A. Escobedo and E. A. Muller, Soft Matter, 2008, 4, 1820-1829; (b) M. A. Bates and M. Walker, Soft Matter, 2009, 5, 346-353; (c) X. H. Liu, K. D. Yang and H. X. Guo, J. Phys. Chem. B, 2013, 117, 9106-9120.

7 (a) S. George, C. Bentham, X. Zeng, G. Ungar and G. A. Gehring, Phys. Rev. E: Stat., Nonlinear, Soft Matter Phys., 2017, 95, 062126; (b) W. S. Fall, C. Nurnberger, X. B. Zeng, F. Liu, S. J. Kearney, G. A. Gehring, C. Tschierske and G. Ungar, Mol. Syst. Des. Eng., 2019, 4, 396-406.
8 (a) B. Chen, U. Baumeister, S. Diele, M. K. Das, X. B. Zeng, G. Ungar and C. Tschierske, J. Am. Chem. Soc., 2004, 126, 8608-8609; (b) M. Prehm, F. Liu, U. Baumeister, X. Zeng, G. Ungar and C. Tschierske, Angew. Chem., Int. Ed., 2007, 46, 7856-7859; (c) A. Lehmann, A. Scholte, M. Prehm, F. Liu, X. B. Zeng, G. Ungar and C. Tschierske, Adv. Funct. Mater., 2018, 28, 1804162.

9 H. J. Kim, Y. H. Jeong, E. Lee and M. Lee, J. Am. Chem. Soc., 2009, 131, 17371-17375.

10 B. Glettner, F. Liu, X. Zeng, M. Prehm, U. Baumeister, G. Ungar and C. Tschierske, Angew. Chem., Int. Ed., 2008, 47, 6080-6083.

11 (a) H. J. Kim, S. K. Kang, Y. K. Lee, C. Seok, J. K. Lee, W. C. Zin and M. Lee, Angew. Chem., Int. Ed., 2010, 49, 8471-8475; (b) H. J. Kim, F. Liu, J. H. Ryu, S. K. Kang, X. Zeng, G. Ungar, J. K. Lee, W. C. Zin and M. Lee, J. Am. Chem. Soc., 2012, 134, 13871-13880.

12 G. Hennrich, A. Omenat, I. Asselberghs, S. Foerier, K. Clays, T. Verbiest and J. L. Serrano, Angew. Chem., Int. Ed., 2006, 45, 4203-4206.

13 T. Hahn, International Tables for Crystallography, Springer, Dordrecht, 5th edn, 2005, vol. A, pp. 105-106.

14 J. L. Locher and M. C. Escher, Escher: The Complete Graphic Work, Thames and Hudson Ltd, London, 1992.

15 B. Chen, U. Baumeister, G. Pelzl, M. K. Das, X. Zeng, G. Ungar and C. Tschierske, J. Am. Chem. Soc., 2005, 127, 16578-16591.

16 M. Poppe, C. L. Chen, F. Liu, M. Prehm, S. Poppe and C. Tschierske, Soft Matter, 2017, 13, 4676-4680. 